\title{
DESIGN OF LABORATORY TEST EQUIPMENT FOR TESTING THE HYDROSTATIC TRANSDUCERS
}

\author{
Jozef NOSIAN ${ }^{1 *}$, L'ubomír HUJO', Marcin ZASTEMPOWSKI ${ }^{2}$, Romana JANOUŠKOVÁ \\ ${ }^{1}$ Slovak University of Agriculture in Nitra, Slovakia \\ ${ }^{2}$ UTP University of Science and Technology, Bydgoszcz, Poland
}

\begin{abstract}
The article presented describes a new design of measuring chains in laboratory test equipment, which are used for testing the hydrostatic transducers and hydraulic fluids. Laboratory test equipment allows simultaneous observation of parameters of hydrostatic transducers and hydraulic fluids by simulating the operating conditions under laboratory conditions, what can significantly reduce the testing time and economic costs. The new design functionality was verified via measurement of the basic parameters of hydrostatic transducers and changing the load of hydraulic fluids. Based on the results measured, the flow efficiency of tested hydrostatic transducer UD-25R was calculated and compared with the transducer parameters specified by the manufacturer using different types of operating hydraulic fluids. Verification measurements of the unloaded hydrostatic transducer were performed at various rotation speeds: $Q_{250}=5.694 \mathrm{dm}^{3} \cdot \mathrm{rpm}$ at speed of $n_{1}=250 \mathrm{rpm} ; Q_{500}=12.286 \mathrm{dm} \cdot \mathrm{rpm}^{3}$ speed of $n_{2}=500 \mathrm{rpm} ; Q_{750}=18.747 \mathrm{dm}^{3} \cdot \mathrm{rpm}$ at speed of $n_{3}=750 \mathrm{rpm}$. Based on the hydrostatic transducer flow rate, the UD-25R transducer flow efficiency was determined: at $n_{1}=250 \mathrm{rpm}$, the flow efficiency was $\eta_{250}=0.8946$; at $n_{2}=500 \mathrm{rpm}$, the efficiency was $\eta_{500}=0.9651$; at $n_{3}=750 \mathrm{rpm}$, the flow efficiency was $\eta_{750}=0.9812$.
\end{abstract}

Keywords: hydraulic pump; hydraulic circuits; measuring chain; verification measurement; hydraulic equipment

Hydraulic systems and equipment have become an important part of almost all types of machines in order to increase the efficiency and energy transfer. Due to their wide use, increasing demands are put on hydraulic systems - this applies to both hydrostatic transducers and hydraulic fluids used in hydraulic systems. Kučera et al. (2016) reported that it is possible to determine the technical condition of hydraulic elements in hydraulic systems based on the operating fluid analysis. There are high requirements for hydraulic fluids that serve as energy carriers in hydraulic systems. Producers must take into account the demands for their quality improvement and environmental burden reduction (Kosiba et al., 2016a). A comprehensive analysis of the effects of biological fluids and mixtures has already been performed by Puškár et al. (2019). Čorňák (2018) has also dealt with this topic. Recently, the operation and development of hydraulic systems has focused on ecological operation, which uses hydraulic systems to mitigate the environmental pollution. For this reason, ecological fluid carriers are increasingly used in hydraulic circuits. The need for testing the agricultural machinery in terms of its suitability for agricultural use will continuously grow, because the machinery has direct impacts on agricultural production (Tkáč et al., 2017). The device proposed can be also used for tribodiagnostics of oil or individual hydraulic elements in hydraulic circuit. Tribodiagnostics utilizes the oils as media for obtaining the information on processes and changes in the systems, in which they occur (Halenár and Kuchar, 2017). The investigation of hydraulic devices used in industry was also dealt by Simikič et al. (2014) and Markiewicz-Patalon et al. (2018). The proposed device was used to test the parameters of hydrostatic converters. According to Kosiba et al. (2019), the design of the proposed device must meet certain requirements under measurement conditions, i.e., the oil temperature and speed of the hydrostatic transducers are especially important.

\section{Material and methods}

According to Tkáč et al. (2010), when determining the correct function of the hydrostatic transducer, it is important to monitor the flow rate, which can be used for calculation of the flow efficiency. The measuring chain measures the parameters of hydrostatic transducers. The proposed laboratory test equipment allows more options for connecting the measuring chain consisting of two hydraulic circuits - there is one primary and one secondary measuring chain, enabling continuous and simultaneous test of two pumps or two types of hydraulic under the same conditions.

In accordance with the SAE J745 standard, prior to verification measurement, the working fluid PARAMO $\mathrm{HM} 46$ was heated to a working temperature of $50{ }^{\circ} \mathrm{C}$ in the secondary hydraulic circuit of measuring chain. Subsequently, the required rotation was set, at which the verification was to be performed. The pump was measured at following rotations:

$$
-n_{1}=250 \mathrm{rpm} \text {, }
$$




$$
-n_{2}=500 \mathrm{rpm} \text {, }
$$$$
-n_{3}=750 \mathrm{rpm} \text {. }
$$

$$
n=t_{a}^{2} \frac{s}{\Delta^{2}}
$$

At each of these rotations, the measurements were performed; based on the measured values, three critical values were determined and then compared and evaluated afterwards.

The minimum necessary number of repetitions was determined as follows:

Table 1

Results of mathematical and statistical analysis for determination of the minimum required number of repetitions when measuring the hydrostatic transducer flow

\begin{tabular}{|l|c|}
\hline \multicolumn{2}{|c|}{ Input parameters } \\
\hline \hline Required accuracy $\Delta\left(\mathbf{d m}^{\mathbf{3}} \cdot \mathbf{r p m}\right)$ & 0.9 \\
\hline Maximum permissible error $\delta(\%)$ & 4.0 \\
\hline Critical value of normal distribution, $\boldsymbol{t}_{\alpha}-\mathbf{9 0} \%$ & 1.645 \\
\hline Critical value of normal distribution, $\boldsymbol{t}_{\beta}-\mathbf{9 0 \%}$ & 1.282 \\
\hline
\end{tabular}

\begin{tabular}{|l||c|c|c|}
\hline \multicolumn{3}{|c|}{ The resulting calculated parameters of the minimum number of repetitions } \\
\hline & \multicolumn{3}{|c|}{ rotation speed of hydrostatic transducer $\mathbf{~ H H}$ (rpm) } \\
\cline { 2 - 4 } & $\mathbf{2 5 0}$ & $\mathbf{5 0 0}$ & $\mathbf{7 5 0}$ \\
\hline $\begin{array}{l}\text { For the value of the normal } \\
\text { distribution } \boldsymbol{t}_{\alpha}\end{array}$ & 2 & 2 & 2 \\
\hline $\begin{array}{l}\text { For the value of the normal } \\
\text { distribution } \boldsymbol{t}_{\beta}\end{array}$ & 1 & 1 & 1 \\
\hline For $\delta \cdot \boldsymbol{v}_{\boldsymbol{k}}^{-1}$ & 1 & 1 & 1 \\
\hline
\end{tabular}

\begin{tabular}{|c|c|}
\hline \multicolumn{2}{|c|}{ Input data } \\
\hline Measuring ranges $\left(\mathrm{dm}^{3} \cdot \mathrm{rpm}\right)$ & Operating pressure ( $\mathrm{MPa})$ \\
\hline $1.2-20$ & 40 \\
\hline $6.0-60$ & 40 \\
\hline $15.0-300$ & 40 \\
\hline $40.0-600$ & 31.5 \\
\hline \multicolumn{2}{|c|}{ Input data } \\
\hline $\begin{array}{l}\text { Output signal, allowable load } \\
\text { resistance }\end{array}$ & $4-20 \mathrm{~mA}, R_{L \max }=\left(U_{B}-10 \mathrm{~V} / 20 \mathrm{~mA}, \mathrm{k} \Omega\right)$ \\
\hline Accuracy & $\leq 2 \%$ real value \\
\hline \multicolumn{2}{|c|}{ Additional data } \\
\hline Compensated temperature range & from -20 to $+70^{\circ} \mathrm{C}$ \\
\hline Operating temperature range & from -20 to $-70{ }^{\circ} \mathrm{C}$ \\
\hline Fluid temperature range & from -20 to $-90{ }^{\circ} \mathrm{C}$ \\
\hline Protection class & IP 65 \\
\hline Supply voltage & $10-32 \mathrm{~V}$ \\
\hline Residual ripple of the supply voltage & $\leq 5 \%$ \\
\hline Viscosity range & $1-100 \mathrm{~mm}^{2} \cdot \mathrm{s}^{-1}$ \\
\hline Calibration viscosity & $30 \mathrm{~mm}^{2} \cdot \mathrm{s}^{-1}$ \\
\hline
\end{tabular}

Table 2 Technical data of the HYDAC EVS 3100 sensor $s \quad$ - estimated standard deviation of the base set

Table 1 shows the results of mathematical and statistical analysis necessary to determine the minimum required number of repetitions when measuring the flow of the hydrostatic transducer.

The determination of the individual hydraulic device components for assessing the operation of hydraulic pumps and energy carriers is as follows (Tkáč et al., 2017):

Hydrostatic transducer flow:

$$
Q=\frac{v_{g} \cdot n}{1000} \cdot \eta_{f l}, \quad \mathrm{dm}^{3} \cdot \mathrm{rpm}
$$

where:

$V_{g}$ - hydrostatic transducer volume, $\mathrm{dm}^{3}$

$n$ - hydrostatic transducer rotation speed rotation, rpm

$\eta_{f l}$ - hydrostatic transducer flow efficiency

Hydrostatic transducer power:

$$
P=\frac{V_{g} \cdot n \cdot p}{60 \cdot 1000 \cdot \eta_{c}}, \quad W
$$

where:

$p$ - pressure, $\mathrm{MPa}$

$\eta_{c}$ - overall effectiveness Inner diameter of the pipe:

$d=\sqrt{\frac{4 \cdot Q}{\pi \cdot w}}, \quad \mathrm{~mm}$

where:

$w$ - resistance to flow rate, $\mathrm{m} \cdot \mathrm{s}^{-1}$

Cooling power:

$$
P_{0}=P_{01} \cdot 1.1, \quad W \cdot{ }^{\circ} \mathrm{C}^{-1}
$$

Specific cooling power:

$$
P_{01}=\frac{P_{v}}{T_{1}-T_{2}}, \quad W \cdot{ }^{\circ} C^{-1}
$$

where:

$P_{v} \quad$ - cooling power, $\mathrm{W}$

$T_{1}$ - maximum temperature, ${ }^{\circ} \mathrm{C}$

$T_{2}$ - minimum temperature, ${ }^{\circ} \mathrm{C}$

Measurement of physical quantities in the hydraulic system under operating conditions was performed using associated sensors (HYDAC International EVS 3 100). Following quantities are the most frequently measured qualities in hydraulic circuits: pressure, temperature, and 
Table 3 Technical parameters of hydraulic pump UD-25R

\begin{tabular}{|l||c|c|}
\hline Parameter & Unit & Value \\
\hline Rated rotation & \multirow{2}{*}{$\mathrm{rpm}$} & 1500 \\
\hline Maximum rotation & & 3200 \\
\hline Minimum rotation & \multirow{2}{*}{$\mathrm{MPa}$} & 450 \\
\hline Maximal pressure at the inlet & & 0.05 \\
\hline Minimum inlet pressure & $\mathrm{MPa}$ & 0.03 \\
\hline Nominal outlet pressure & & 20 \\
\hline Maximum outlet pressure & $\mathrm{dm}^{3}$ & 23 \\
\hline Geometric volume & \multirow{2}{*}{$\mathrm{mm}^{2} \cdot \mathrm{s}^{-1}$} & 0.02546 \\
\hline Maximum oil viscosity & & $1 \mathrm{t} 200$ \\
\hline Minimum oil viscosity & \multirow{2}{*}{$\mathrm{C}$} & 10 \\
\hline Maximum oil temperature & & 80 \\
\hline Minimum oil temperature & & -20 \\
\hline
\end{tabular}

Table 4 Characteristics of PARAMO HM 46 oil

\begin{tabular}{|l|c|c|}
\hline Parameter & Unit & PARAMO HM 46 \\
\hline Point of fluidity & ${ }^{\circ} \mathrm{C}$ & -27 \\
\hline Flash point & ${ }^{\circ} \mathrm{C}$ & over 190 \\
\hline Inflammability & - & fourth hazard class \\
\hline Vapour pressure at $\mathbf{2 0}^{\circ} \mathbf{C}$ & $\mathrm{Pa}$ & $<10$ \\
\hline Relative density at $\mathbf{1 5}^{\circ} \mathbf{C}$ & $\mathrm{kg} \cdot \mathrm{m}^{-3}$ & 865 \\
\hline Solubility & - & insoluble in water \\
\hline Auto-ignition temperature & ${ }^{\circ} \mathrm{C}$ & over 320 \\
\hline Kinematic viscosity at $\mathbf{4 0}{ }^{\circ} \mathbf{C}$ & $\mathrm{mm}^{2} \cdot \mathrm{s}^{-1}$ & $41.4-50.6$ \\
\hline Explosive properties & - & it is not explosive \\
\hline Oxidizing properties & - & it is not oxidizing \\
\hline
\end{tabular}

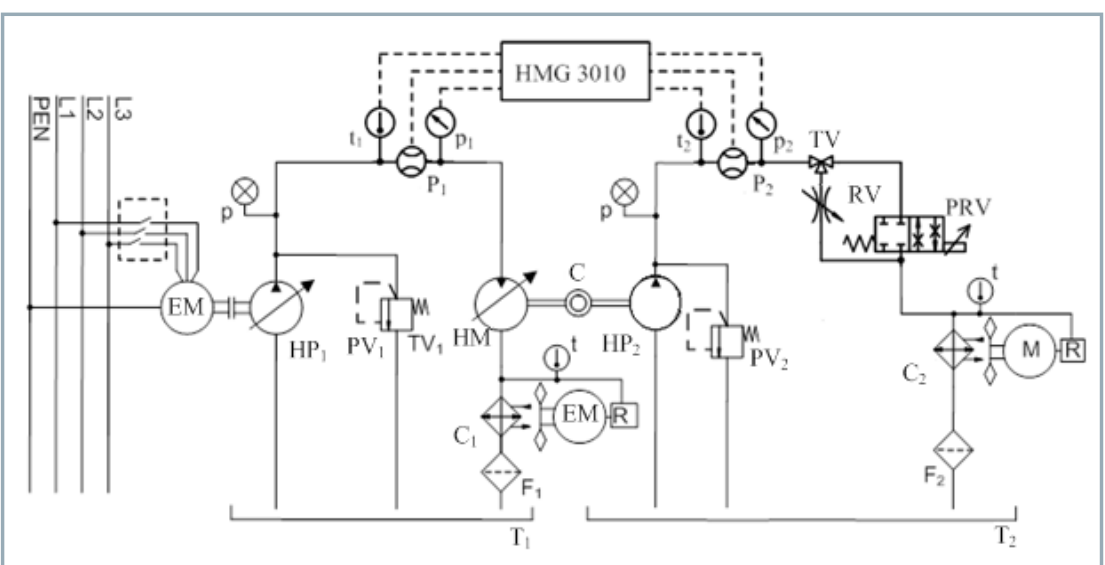

Fig. 1 Laboratory equipment for measuring the parameters of hydrostatic transducers

$\mathrm{EM}$ - electromotor; $\mathrm{HP}_{1}$ - regulatory hydraulic pump; $\mathrm{PV}_{1}, \mathrm{PV}_{2}$ - pressure valve; $\mathrm{HM}$ regulatory hydraulic motor; $\mathrm{HP}_{2}$ - tested hydraulic pump; $\mathrm{C}_{1}, \mathrm{C}_{2}$ - cooler; $\mathrm{t}$-temperature sensor for tanks; $p$ - pressure gauge; RV - reducing valve; TV - three-way valve; PRV - proportional reducing valve; $\mathrm{C}$ - coupler; $\mathrm{R}$ - regulator of electric motor; $\mathrm{t}_{1}$ $t_{2}$ - ETS 4148-H-006-000 temperature sensors; $P_{1}, P_{2}$ - EVS 3108-H-0300-000 flow rate sensors; p1, p2 - HDA 4748-H-0400-000 pressure sensors; HMG 3010 - recording unit flow, since they are the main indicators of technical condition of hydraulic circuit elements. Associated sensors were used for measuring the physical quantities and recorded values were transmitted to the HYDAC HMG 3010 recording unit. These sensors were in the primary and secondary hydraulic circuit and their technical are given in Table 2.

HYDAC HMG 3010 measuring device was used to record and display the measured values. The device contains: advanced voltage measurement in ranges from -10 to $+10 \mathrm{~V}$ and from 0 to $50 \mathrm{~V}$. It offers the possibility of recording signals on two inputs in $0-50 \mathrm{~V}$ range, and on one input from -10 to $+10 \mathrm{~V}$ range. The device protection class is IP 40 . The device maximum inaccuracy is $\pm 1 \%$.

The aforementioned relations determine the basic element parameters of laboratory test equipment hydraulic circuit. Other elements of the measuring chain were dimensioned based on the technical data in the product catalogue of hydraulic elements. Table 3 shows the technical parameters of the UD-25R hydrostatic transducer specified by the manufacturer.

PARAMO HM 46 hydraulic fluid was used as the hydraulic charge in the secondary hydraulic circuit. It is mainly intended for hydrostatic hydraulic mechanisms. Its properties are listed in Table 4.

\section{Results and discussion}

Fig. 1 shows a schematic circuit of newly designed laboratory test equipment for measuring and testing the hydrostatic transducers and working fluids used in hydraulic equipment. The proposed device consists of two hydraulic circuits: the primary circuit is connected to the electric motor (EM), and the secondary circuit is connected to the hydraulic pump (HP2).

Fig. 2 shows the equipment for measuring the parameters of hydrostatic transducers and hydraulic fluids, which was used for performing the life tests of hydrostatic transducers in parallel using two different working fluids. According to Kosiba et al. (2016b), it is important to monitor the parameters of hydrostatic transducers under operating conditions. 


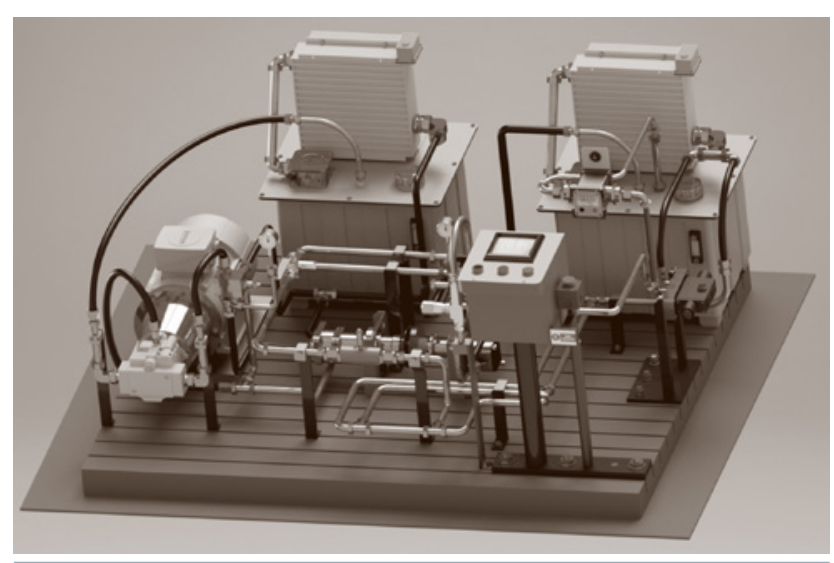

Fig. 2 Test equipment for measuring the parameters of hydrostatic transducers

The measuring chain is used to measure the parameters of hydrostatic transducers and allows several possibilities of its connection. The proposed design allows to test two hydrostatic transducers or two types of hydraulic fluids in parallel, either under the same conditions, or to simulate the operating load. An asynchronous electric motor connected to a hydrostatic transducer via a mechanical coupling was used to drive the pump in the primary circuit. The circuit includes a pressure valve, which is in both the primary and secondary circuits, and performs the function of a safety valve and prevents the occurrence of a hazardous condition. A cooler for temperature regulation of working fluids is included in both the primary and secondary circuits. This also applies to a filter and a tank with the same volume in each circuit. A hydro-engine for conversion of pressure energy to mechanical energy is included in the primary circuit and connected to a hydrostatic transducer in the secondary circuit via a mechanical coupling. Considering the secondary circuit, a three-way valve for fluid flow control and a throttle valve for deriving the load in hydraulic circuit are included. Furthermore, there is also a proportional valve for deriving the load and simulating the operating pressures. Sensors for recording rotation, temperature, flow

Table 5

Verification of average flow value obtained in verification measurement with a constant given by the hydrostatic transducer manufacturer

\begin{tabular}{|c|c|c|}
\hline \multicolumn{3}{|c|}{ Input parameters } \\
\hline Parameter & Marking & Value \\
\hline Significance level & $\alpha$ & 0.050 \\
\hline Set of values & $\mathrm{n}$ & 50 \\
\hline Critical value & $\mu_{0}$ & 1.960 \\
\hline \multicolumn{3}{|c|}{ Calculated values of the test criterion $\mathrm{m}$} \\
\hline \multicolumn{3}{|c|}{ Rotation speed of hydrostatic transducers $\mathrm{nH}, \mathrm{rpm}$} \\
\hline 250 & 500 & 750 \\
\hline 18.80 & 51.92 & 73.70 \\
\hline
\end{tabular}

Legend: cells indicating the increased flow rates in contrast to values specified by the manufacturer; cells indicating the reduced flow rates in contrast to values specified by the manufacturer and pressure were added to the hydraulic circuit. These sensors are connected to the HYDAC HMG 3010 recording unit, through which the parameters during the verification measurement were recorded.

Experimental measurements of hydrostatic transducers under laboratory conditions are of great importance, especially in relation to the testing of basic parameters. In these measurements, it is possible to simulate various states and test the transducers before they are put into practice, and the same applies to hydraulic fluids. This means that the manufacturers of hydrostatic transducers and hydraulic fluids can modify their products based on the measurement results. Concurrently, experimental measurements can also be used to create dynamic flow models of hydrostatic transducers in order to compare individual parameters.

Verification of the measuring chain for measuring and testing of hydrostatic transducers was conducted in order verify whether the pump, hydraulic circuit elements and designed measuring chains operate appropriately. Prior to verification measurement itself, it was necessary to calibrate the sensors and, during the verification measurement, the flow of the UD-25R pump in the secondary hydraulic circuit of the measuring chain was observed.

Flow and flow efficiency values were used to create dynamic flow models in hydrostatic transducers using numerical simulation to protect the environment (Puškár et al., 2015). When verifying the measurement of a given measuring chain, the first step is to heat the working fluid to an operating temperature of $50^{\circ} \mathrm{C}$. Based on the settings of the HYDAC HMG 3010, the hydrostatic transducer flow was measured for 1 minute, with $0.100 \mathrm{~ms}$ sampling, and recorded 600 samples of hydrostatic transducer flow data. For a given measurement of the measuring chain, the hydraulic circuit was observed without load. At each rotation speed, measurements were performed and three critical values were determined for comparison and evaluation.

Flow efficiency of hydrostatic transducer in verification measurement UD-25 R (sample calculation) is as follows:

$$
\eta=\frac{Q}{V_{G} \cdot n} 100=\frac{5.694}{0.02546 \cdot 250} \cdot 100=89.46 \%
$$

The measured data with basic statistics are shown in Table 6.

Table 6 Measured data with basic statistics

\begin{tabular}{|l||c|c|c|}
\hline Rotation speed & 250 rpm & $\mathbf{5 0 0} \mathbf{~ r p m}$ & $\mathbf{7 5 0} \mathbf{~ r p m}$ \\
\hline Arithmetic mean & 5.694 & 12.286 & 18.747 \\
\hline Maximum value & 5.930 & 12.390 & 18.850 \\
\hline Minimum value & 5.330 & 12.130 & 18.590 \\
\hline Medium value & 5.760 & 12.300 & 18.760 \\
\hline Number of measurements & 50 & 50 & 50 \\
\hline Modus & 5.850 & 12.300 & 18.760 \\
\hline Median & 5.760 & 12.300 & 18.760 \\
\hline Standard deviation & 0.176 & 0.061 & 0.0550 \\
\hline Coefficient of variation (\%) & 3.100 & 0.499 & 0.294 \\
\hline
\end{tabular}




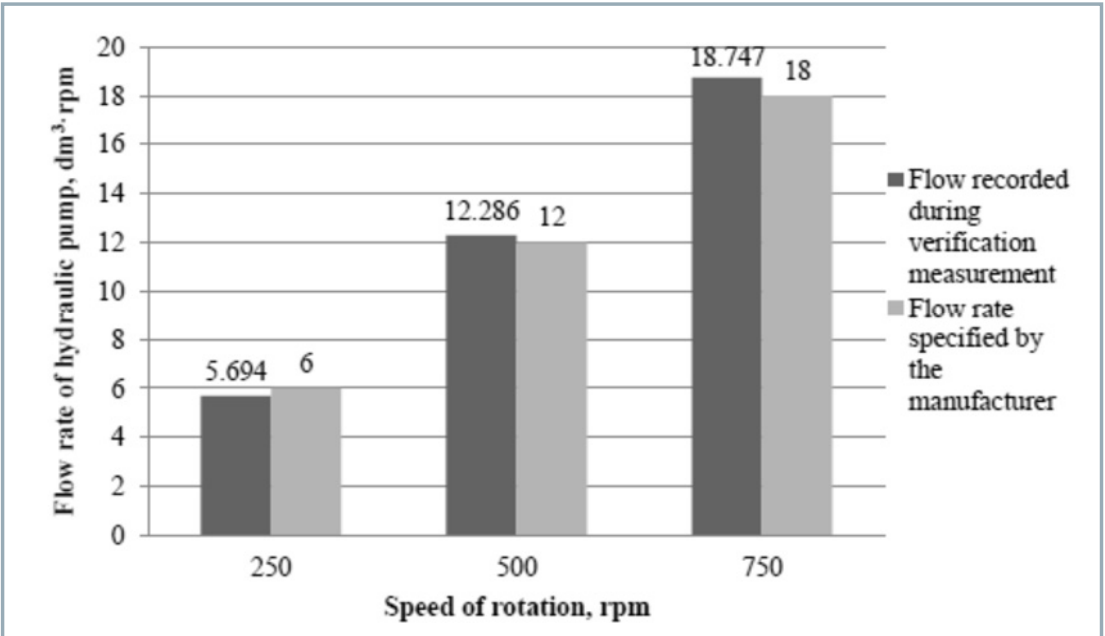

Fig. 3 Hydraulic pump flow values recorded during the verification measurement and flow values specified by the manufacturer

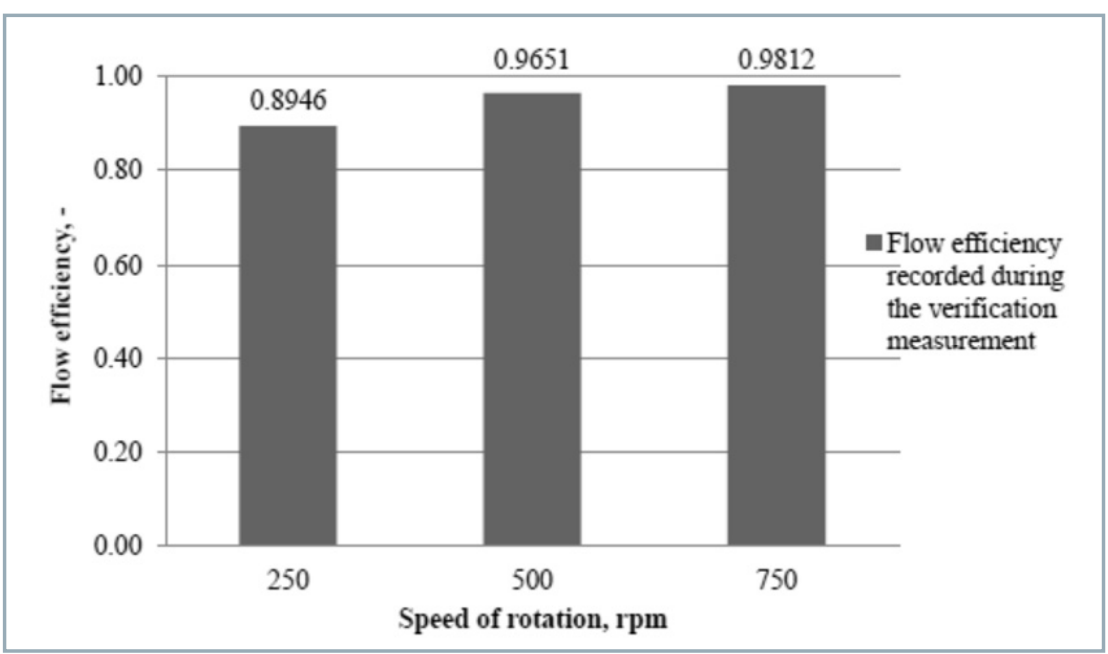

Fig. 4 Flow efficiency values of the UD-25 R hydraulic pump calculated from the values obtained during the verification measurement

During data evaluation from verification measurement, there was observed a decrease in flow of hydrostatic transducer by $5.1 \%$ at $n_{1}=$ $250 \mathrm{rpm}$ compared to the data given by manufacturer. At rotation speeds $n_{2}=500 \mathrm{rpm}$ and $n_{3}=750 \mathrm{rpm}$, there was an increase in flow by $2.38 \%$ and $4.15 \%$, respectively, compared to the data provided by manufacturer.

Fig. 3 shows the hydrostatic transducer flow data observed during the verification measurement and the flow data provided by manufacturer. The differences in values can be explained by different measurement conditions: the manufacturer assumes a temperature of $45{ }^{\circ} \mathrm{C}$, while the verification measurement was performed at an operating temperature the speed was intentionally set in the first third of the pump rotation range. Minav et al. (2017) recorded the maximum gear hydraulic pump flow efficiency at the level of $\eta=0.91$, however, based on the experiment conducted, higher values were recorded. Differences in values can be due to several factors, e.g. Minav et al. (2017) used a different type of hydraulic fluid in their measurement and loaded the hydraulic pump with a working pressure of $5 \mathrm{MPa}$ at the same time. Kosiba et al. (2019) recorded the rotary gear hydraulic pump flow efficiency with external gearing of $\eta=0.9745$ at $1500 \mathrm{rpm}$. The authors used a UD-20 pump with a different type of hydraulic fluid than it was used in the verification measurement presented. Simultaneously, they carried out the measurement in practice, i.e., during the tractor operation. Rizzo et al. (2015) observed the efficiency of hydraulic pump loaded with pressure at the level of 0.92 .

Test laboratory equipment for measuring the parameters of hydrostatic transducers and hydraulic fluids allows the connection of several types of measuring chains. After modifications, it is possible to connect other types of measuring chains to the given device, making it usable for measuring the parameters of hydrostatic transducer, pumps or hydro-engine, or determination of properties of hydraulic fluids. For one type of measuring chains, it is possible to test the parameters of hydrostatic transducers or hydraulic fluids depending on the operating pressure and temperature, or the maximum pressure and temperature. The next measuring chain monitors the properties of hydraulic fluids during a step change in pressure in the hydraulic system. The designed test equipment allows several options for the connection of hydrostatic transducers and controls due to its modularity. For this reason, the proposed device can be used to test the parameters of hydrostatic transducers, hydraulic elements, or properties of hydraulic fluids depending on different conditions.

The results obtained point out the following benefits:

- on the basis of proposed laboratory test equipment, it is possible to 
shorten the operational testing time of hydrostatic transducers, hydraulic fluids and hydraulic elements;

- utilizing the laboratory test equipment, it is possible to simultaneously test the parameters of two hydrostatic transducers;

- on the basis of acquired knowledge and measurement results of the hydrostatic transducer, it is possible to make changes in the construction of devices in question prior to their introduction to the production process;

- at the same time, it is possible to use the obtained hydrostatic transducer flow results to create dynamic flow models.

\section{Conclusion}

The aim of presented research was to design a device that will be used for testing the parameters of hydrostatic transducers and properties of hydraulic fluids. Thanks to the designed laboratory test equipment, it is possible to shorten the testing time of hydrostatic transducers and hydraulic fluids, and, at the same time, the equipment allows repeatability of measurements. The device proposed allows the connection of several types of measuring chains for measuring and testing the parameters of hydrostatic transducers and hydraulic fluids. The device described can test two hydraulic fluids simultaneously under the same or different conditions and allows to repeatedly simulate the operating conditions of agricultural and forestry machinery.

With the help of verification measurement, the functionality of the subject measuring chain used for measuring and testing the parameters of hydrostatic transducers and hydraulic fluids in laboratory conditions was demonstrated. The test laboratory equipment proposed allows the creation of several types of measuring chains, which can be used to measure and test the properties of hydraulic fluids, parameters of hydrostatic transducers and hydraulic circuit elements. Utilizing the proposed laboratory test equipment, it is possible to shorten the operational testing time of hydrostatic transducers, hydraulic fluids and hydraulic elements.

\section{Acknowledgements}

This work was supported by project VEGA 1/0155/18 "Applied research of the use of ecological energy carriers in agricultural, forestry and transport technology".

This work was supported by project KEGA 028SPU4/2019"Practical utilization of design and testing knowledge of transmission systems of hydraulic mechanisms of mobile agricultural and forestry machinery".

This work was supported by project APVV SK-PL-180041 "The development of scientific cooperation in the study of the effects of biofuels in road transport, including environmental impact".

\section{References}

ČORŇÁK, Š. 2018. Identification of operating fluids with fingerprint method utilization. In $17^{\text {th }}$ International Scientific Conference "Engineering for Rural Development", Jelgava, Latvia, pp. 2048-2053.
HALENÁR, M. - KUCHAR, P. 2017. Research of biodegradable fluid during operating test. In $24^{\text {th }}$ International PhD Students Conference for Undergraduate and Postgraduate Students (MendeINet), Brno, Czech Republic, pp. 784-789.

KOSIBA, J. - ČORŇÁK, Š. - GLOS, J. - JABLONICKÝ, J. - VOZÁROVÁ, V. -PETROVIČ, A. - CSILLAG, J. 2016a. Monitoring oil degradation during operating tests. In Agronomy Research, vol. 14, no. 5, pp. 1626-1634.

KOSIBA, J. - JABLONICKÝ, J. - BERNÁT, R. - KUCHAR, P. 2016b. Effect of ecological hydraulic fluid on operation of tractor hydraulic circuit. In Trends in Agricultural Engineering 2016, pp. 317-322.

KOSIBA, J. - JABLONICKÝ, J. - BERNÁT, R. - ZÁLEŽÁK, Z. 2019. Flow characteristics of the tractor hydraulic circuit by application of the biodegradable synthetic fluid. In Trends in Agricultural Engineering 2019, pp. 269-274.

KUČERA, M. - ALEŠ, Z. - PEXA, M. 2016. Detection and characterization of wear particles of universal tractor oil using of particles size analyzer. In Agronomy Research, vol. 14, no. 4, pp. $1351-1360$

MARKIEWICZ-PATALON, M. - MUŚLEWSKI, L. - KASZKOWIAK, J. SÓJKA, M. 2018. Analysis of efficiency of the vehicle transport facilities powered with diesel oil with additive of biocomponent. In IOP Conference Series Materials Science and Engineering, vol. 421, no. 4. pp. 1-8.

MINAV, T. - HEIKKINEN, J. - PIETOLA, M. 2017. Direct driven hydraulic drive for new powertrain topologies for non-road mobile machinery. In Electric Power Systems Research, vol. 152, pp. 390-400.

PUŠKÁR, M. - BRESTOVIČ, T. - JASMINSKÁ, N. 2015. Numerical simulation and experimental analysis of acoustic wave influences on brake mean effective pressure in thrust-ejector inlet pipe of combustion engine. In International Journal of Vehicle Design, vol. 67, no. 1, pp. 63-67.

PUŠKÁR, M. - JAHNÁTEK, A. - KURIC, I. - KÁDÁROVÁ, J. - KOPAS, M. - ŠOLTÉSOVÁ, M. 2019. Complex analysis focused on influence of biodiesel and its mixture on regulated and unregulated emissions of motor vehicles with the aim to protect air quality and environment. In Air Quality, Atmosphere and Health, vol. 12, no. 7, pp. 1-10.

RIZZO, G. - MASSAROTTI, G. P. - BONANNO, A. - PAOLUZZI, R. RAIMONDO, M. - BLOSI, M. - VERONESI, F. - CALDARELLU, A. GUARINI, G. 2015. Axial piston pumps slippers with nano-coated surfaces to reduce friction. In International Journal of Fluid Power, vol. 16, pp. 1-10.

SIMIKIČ, M. - DEDOVIČ, N. - SAVIN, L. - TOMIČ, M. - PONJIČAN, O. 2014. Power delivery efficiency of a wheeled tractor at oblique drawbar force. In Soil and Tillage Research, vol. 141, pp. 32-43.

TKÁČ, Z. - ČORŇÁK, Š. - CVIKLOVIČ, V. - KOSIBA, J. - GLOS, J. JABLONICKÝ, J. - BERNÁT, R. 2017. Research of biodegradable fluid impacts on operating of tractor hydraulic system. In Acta Technologica Agriculturae, vol. 20, no. 2, pp. 42-45.

TKÁČ, Z. - MAJDAN, R. - DRABANT, Š. - JABLONICKÝ, J. ABRAHÁM, R. - CVÍČELA, P. 2010. The accelerated laboratory test of biodegradable fluid type "ERTTO". In Research in Agricultural Engineering, vol. 56, no. 1, pp. 18-25.

TULÍK, J. - KOSIBA, J. - SZABÓ, M. - VARGA, F. - KANGALOV, P. MAREČEK, J. 2015. Analysis of new biodegradable fluid during of the operating test. In Agricultural, Forest and Transport Machinery and Technologies, vol. 2, no. 1, pp. 11-15. 